\title{
Variation in foraging patterns as reflected by floral resources used by male vs female bees of selected species at Badlands National Park, SD, USA
}

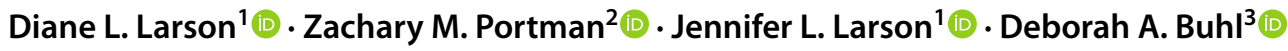

Received: 7 September 2021 / Accepted: 25 December 2021 / Published online: 11 February 2022

This is a U.S. Government work and not under copyright protection in the US; foreign copyright protection may apply 2022

\begin{abstract}
Female and male bees forage for different reasons: females provision nests with pollen appropriate for larval development and consume nectar for energy while males need only fuel their own energetic requirements. The expectation, therefore, is that females should visit fewer floral resource species than males, due to females' focus on host plant species and their tie to the nest location. We used pollen collected from bees' bodies and the flowers they were collected on to infer floral resource use in 2010-2012 at Badlands National Park, SD, USA. We collected bees on 24 1-ha plots centered on particular plant species. We compared number of floral species and families (1) associated with individual female and male bees (via generalized linear mixed models) and (2) accumulated by each sex (using rarefaction); and (3) effect of variation between sexes in plant-bee interactions via modularity analyses. Analyses were restricted to bee species with $\geq 5$ individuals per sex. Contrary to expectation, female and male bees differed infrequently in the number of floral resources they had visited, both on single foraging bouts and collectively when accumulated across all males and females of a species. When males and females did differ, males visited fewer floral species than females. Generalist and specialist bee species did not differ markedly in floral resource use by females and males. When separated by sex, seven of eleven species occupied different modules than they did when analyzed as a species; most of the bee species were connectors, thus important for stability of the network during perturbations.
\end{abstract}

Keywords Badlands $\cdot$ Augochlorella $\cdot$ Bombus $\cdot$ Calliopsis $\cdot$ Diet breadth $\cdot$ Floral resources $\cdot$ Halictus $\cdot$ Lasioglossum . Megachile $\cdot$ Melissodes

\section{Introduction}

Bees are consummate pollinators (Thorp 2000). Reliance on pollen to provision young and, along with nectar, to meet adult energetic requirements, ensure ongoing plant-bee interactions and thus plant sexual reproduction. That said, foraging patterns of female bees can be quite different from those of male bees of the same species (Ne'eman G, et al. 2006; Roswell et al. 2019; Tang et al. 2019; Kishi and Kakutani

Communicated by Heikki Hokkanen.

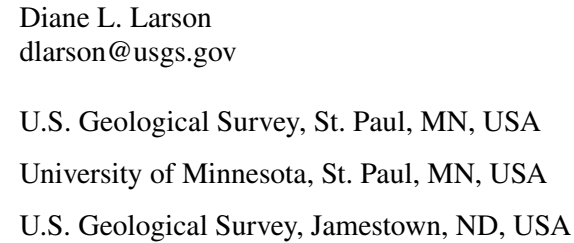

2020): females are essentially central-place foragers around their nest location while males may forage more broadly as they search for mates (Jennersten et al. 1991; Smith et al. 2019b), but see Ogilvie and Thomson (2015). Reproductive output can decline considerably as female foraging distances increase (Zurbuchen et al. 2010) with implications for other fitness components such as proportion of daughters produced and larval survival (Peterson and Roitberg 2006). On the other hand, males of some bee species defend territories, which reduces their foraging range (Smith et al. 2019b). Male mating behavior can strongly determine their overall range; oligolectic species may be most likely to encounter mates at the limited appropriate floral resources, while those females that nest in aggregations are most likely to be encountered at their closely-spaced nests (Paxton 2005).

In addition to sex, there are multiple factors that are thought to influence the degree of ecological specialization in bees, including lecticity and body size (Smith et al. 
2019a). While it is clear that female and male bees forage for different purposes, bee taxa also vary in their foraging preferences; as many as $9 \%$ of bee genera worldwide are oligolectic (i.e. females restrict their pollen foraging to a set of related plants (Linsley and MacSwain 1958)) and such specialists may be found in most lineages (Rasmussen et al. 2020). Again, however, females may have greater likelihood of foraging more narrowly, as the morphology of scopae may limit the sizes of pollen they can carry back to the nest (Roberts and Vallespir 1978; Rasmussen et al. 2020). Body size also has an influence on foraging; larger bees can range over larger areas (Greenleaf et al. 2007; Zurbuchen A, et al. 2010). For example, male Bombus terrestris have been found to have much larger flight ranges than the smaller workers (Kraus et al. 2009); in general, however, male solitary bees are smaller than females of the same species (Helms 1994). Depending on landscape heterogeneity, a larger foraging range may result in more pollen species used by an individual generalist forager. However, generalists with smaller ranges may forage on more species, as a population, if individuals sample small, separate portions of the larger landscape. Individual- and species-level diet breadth may therefore differ. Floral constancy, which refers to the tendency of individual bees to restrict their foraging to one or a few plant species within a single foraging bout (Waser 1986), does not imply the same constancy for the species as a whole (Araujo et al. 2011; Latty and Trueblood 2020).

Discussions of foraging behavior in bees can be tricky due to the potential confounding of different definitions of specialization. Specifically, bees can be pollen specialists, or oligolectic (Linsley and MacSwain 1958), as described above. However, most oligolectic bees are still generalist nectar foragers, and will nectar at plants other than their preferred pollen hosts (Robertson 1925). In many ecological and network studies, "specialization" refers to ecological specialization, or the total number of interactions a bee species has with different plant species, regardless of whether it is gathering pollen (Blüthgen et al. 2006). In addition, even bees that are not gathering pollen still passively accumulate pollen on their bodies (Portman et al. 2019). As a result, ecological specialization can be a poor proxy for oligolecty, especially since male visits are often included in calculations of ecological specialization. In this paper we focus on ecological specialization, which includes foraging for the bees' energetic requirements rather than only for nest provisioning.

Flower-visitor networks are typically constructed without distinguishing or separating the sexes of the flower visitors. When downscaling from species-species pollination networks to individual pollinator-species networks, Tur et al. (2014) found that pollinator species are typically composed of both generalist and specialist individuals; they did not distinguish sexes. Smith et al. (2019b) suggested that networks constructed with separate sexes of insect visitors might be a way forward without the extreme computational resources necessary for individual scale networks. If females and males forage consistently in a sex-specific manner, network metrics could be much more informative by taking these differences into account. For example, if conspecific female and male bees forage on a sufficiently different suite of plant species to be partitioned into separate modules, this structural characteristic, related to our understanding of network stability (Thébault and Fontaine 2010; Grilli et al. 2016), could be altered.

In this study, we use pollen removed from individual bees, plus the species of flower on which they were captured, to infer floral resource use of male and female bees present in our study sites at Badlands National Park (BNP), South Dakota, USA. With this information we test the hypothesis suggested by Smith et al. (2019b), that female bees should have smaller diet breadth than male bees. We also examine whether oligolectic bees have a higher degree of ecological specialization and whether oligolectic and polylectic bees show different patterns of foraging between the sexes. We expect that generalist species in the Halictidae should show little difference in foraging between the sexes. On the other hand, we anticipate female Melissodes species, which often specialize on Asteraceae, will visit fewer plant species and families than males. We also explore the implications of separating male and female bees when calculating network modularity. If females and males forage on different flower species, this could result in their separation into different modules and potentially change our understanding of network stability.

\section{Methods}

The bees used in this study were captured as part of several network analyses conducted at BNP in 2010-2012 (Larson et al. 2014, 2016). Studies in 2010-11 took place on four 1-ha plots surrounding populations of each of three rare plant species in Badlands sparse vegetation complex (Von Loh et al. 1999): Astragalus barrii (mid-May-mid-June), Eriogonum visheri (late June - mid-August), and Ericameria parryi (September-mid-October). The sample periods corresponded to the blooming period of the focal plant. Studies in 2012 took place on 12 1-ha plots in wheatgrass prairie vegetation type (Von Loh et al. 1999), half of which had infestations of Cirsium arvense and half of which did not; these were sampled in late June-mid-July. The sample period corresponded to the peak bloom and early senescence of the focal plant. Hereafter, the studies will be referred to by their focal plant species (A. barrii, E. visheri, E. parryi, and C. arvense). We analyzed data from each study separately because each had different plant species available to foragers. Flower counts 
by species were conducted on the same transects on which we collected insects, but we used variable widths: very abundant flower species were counted within a smaller width, but all were standardized to 2-m for summaries. Flowers were counted approximately weekly on each 1-ha plot for a total of 36, 30, 28, and 58 surveys at A. barrii, E. visheri, E. parryi, and $C$. arvense study sites, respectively.

Insect sampling was done during timed (20 min. per transect) walks on ten 2 -m wide by $75-\mathrm{m}$ long transects at each 1-ha plot. Any insect that was observed to be in contact with the reproductive parts of a flower was hand-netted and placed in a vial charged with ethyl acetate until it became quiet. From the vial, the insect was transferred to a labeled glassine envelope and placed into a larger collecting jar, also charged with ethyl acetate. We did insect surveys on the same days as flower counts at A. barrii, E. visheri, and $E$. parryi sites but at $C$. arvense sites insect surveys were done more often and we completed 89 insect surveys. All captured insects-not only bees-were identified to species or species group. Only those identified to species were used in these analyses. We include the flower species upon which the insect was captured as an indication of resource use, along with pollen on the insect's body, because we only collected those insects contacting reproductive parts of flowers.

Prior to pinning, pollen was removed from the insects' bodies by rubbing a small cube of fuchsin jelly over the entire body, including scopae. The jelly was then carefully melted onto a slide and covered with a cover slip. A thin line of latex paint around the edge of the cover slip helped keep the contents of the slide from evaporating. Pollen was identified and counted using a light microscope at 10-100x; we created a reference collection of pollen from each study site to aid in identification.

\section{Statistical methods}

We used generalized linear models to compare species or family richness of floral resources (pollen species carried plus flower species on which the bee was captured if different from pollen species) between individual male and female bees within species to answer the question, does the average number of floral resources (species or families) used differ between males and females during individual foraging bouts. Each bee species was modeled separately. Only bee species with $\geq 5$ individuals of each sex were used in these analyses. All models were one-way analysis of variance models assuming a Poisson distribution and run using PROC GLIMMIX in SAS (SAS Institute Inc. 2018).

We estimated species and family richness of floral resources used by bees of a single species (with $\geq 5$ individuals of each sex) and sex with rarefaction as implemented with the "exact" method in the specaccum function in Vegan 2.5-4 (Oksanen et al. 2020) for R v. 3.4.2 (R Core Team
Table 1 Number of individuals of each species and sex $(F=$ female, $\mathrm{M}=$ male) captured at sites associated with each study, where $\geq 5$ individuals of each sex were captured

\begin{tabular}{llrrc}
\hline Study & Species & F & M & Total \\
\hline Ericameria parryi & Bombus huntii & 6 & 15 & 21 \\
& Lasioglossum packeri & 10 & 5 & 15 \\
& Melissodes glenwoodensis & 5 & 7 & 12 \\
Cirsium arvense & Augochlorella aurata & 65 & 40 & 105 \\
& Halictus confusus & 10 & 7 & 17 \\
& Lasioglossum albipenne & 30 & 21 & 51 \\
& Lasioglossum pruinosum & 52 & 15 & 67 \\
& Lasioglossum semicaeruleum & 58 & 22 & 80 \\
& Megachile brevis & 11 & 53 & 64 \\
Eriogonum visheri & Calliopsis andreniformis & 34 & 35 & 69 \\
& Lasioglossum packeri & 100 & 5 & 105 \\
Total & & 381 & 225 & 606 \\
\hline
\end{tabular}

2015). Each bee was a sample, grouped according to species, sex and study.

For each bee species used to develop rarefaction curves, we also visualized female and male floral resource use with principal coordinates analysis (McCune and Grace 2002) in the software package PCOrd Version 7.08 (McCune and Mefford 2018). We plotted individual bees in plant species space and enclosed females and males of each bee species in separate envelopes. These plots illustrate overlap between female and male floral resource use, not statistical significance.

To explore potential differences in the sexes in their interactions among species, we compared module affiliations for bees grouped by species with those separated by sex within species. For the modularity analysis we considered all insects captured in each study to be a network, but we report only on bees with $\geq 5$ of each sex, as in the other analyses in this paper. We used the Netcarto software package (Guimera and Amaral 2005) to calculate modularity and a one-sample $\mathrm{t}$-test to determine whether the mean modularity of 100 randomized networks differed from the point estimate of modularity for the observed network. We assigned roles to species as described by Dupont $(2009 ; 2012)$ based on participation coefficient (a measure of connections outside a node's module) and within-module relative degree (a measure of connections within a node's module Guimera and Amaral 2005; Guimera et al. 2007)).

\section{Results}

We collected $\geq 5$ individuals of each sex for only 10 species, one of which occurred at two sites (Table 1). We failed to collect enough individuals of any species at our early season 
A. barrii sites, so this study was not included in further analyses. In all, we identified $>98 \%$ of the pollen grains to species; approximately $1.5 \%$ were only identified to morphospecies and likely originated off-site. During flower surveys we detected only 11 flowering species in four families at the late-season $E$. parryi sites, compared to 59 species in 22 families at $E$. visheri and 59 species in 21 families at $C$. arvense sites, which were sampled mid-season. Mean flowers counted per plant family for each study can be found in Table S1. Data used for analyses presented in this paper can be found at Larson et al. (2018). (Note that the site naming convention in Larson et al. (2018) is different from the one used here: $A$. barrii $=$ sp-early, E. visheri $=s p$-mid, E. parryi $=$ sp-late, and $C$. arvense $=w g$ - mid.)

The mean number of species of floral resources per individual bee (i.e., within a single foraging bout) differed between males and females for three bee species-by-study combinations: Melissodes glenwoodensis at E. parryi sites, Lasioglossum semicaeruleum at $C$. arvense sites and $\mathrm{Cal}$ liopsis andreniformis at E. visheri sites (Table 2). In each case, and contrary to our expectation for the two oligolectic species (M. glenwoodensis and $C$. andreniformis), individual females were associated with a greater number of floral resource species than individual males. Only $C$. andreniformis females and males differed in floral family use: females visited more families than did males, again contradicting our hypothesis (Table 2).

Rarified accumulation curves for males and females by bee species illustrate the differences in total accumulation of floral resource species (Fig. 1) or families (Figure S1) as more individuals of a bee species were sampled. At E. parryi sites the polylectic Bombus huntii (Fig. 1a) and oligolectic M. glenwoodensis (Fig. 1c) floral resource species richness diverged, with male $B$. huntii accumulating more floral species than females but the reverse was true for M. glenwoodensis. This trend was also reflected in family floral resources: female B. huntii (Figure S1a) and male M. glenwoodensis (Figure S1c) only used floral resources in the Asteraceae. Lasioglossum spp. males and females accumulated similar numbers of floral resource species (Fig. 1b,f,g,h,k) and families (Figure S1b,f,g,h,k) at all three study areas, although the trajectory of male L. semicaeruleum at the $C$. arvensis sites (Figure S1h) suggested a leveling-off with respect to floral resource families. Polylectic Augochlorella aurata (Figs. 1d and S1d) and Megachile brevis (Figs. 1i and S1i) male and female accumulation curves, for both species and families, overlapped broadly. In contrast, male $C$. andreniformis

Table 2 Back-transformed least square mean and standard error of number of floral resources (species or families) associated with female or male bees

\begin{tabular}{|c|c|c|c|c|c|}
\hline Study & Bee species & Plant level & Statistic & Female mean (SE) & Male mean (SE) \\
\hline \multirow[t]{3}{*}{ Ericameria parryi } & Bombus huntii & Species & $F_{1,19}=0.57 ; p=0.4584$ & $1.5(0.5)$ & $2(0.37)$ \\
\hline & Lasioglossum packeri & Species & $F_{1,13}=0.56 ; p=0.4663$ & $1.3(0.36)$ & $1.8(0.6)$ \\
\hline & Melissodes glenwoodensis & Species & $F_{1,10}=7.88 ; p=0.0186$ & $4.2(0.92)$ & $1.4(0.45)$ \\
\hline \multirow[t]{6}{*}{ Cirsium arvense } & Augochlorella aurata & Species & $F_{1,103}=2.17 ; p=0.1435$ & $1.55(0.15)$ & $1.2(0.17)$ \\
\hline & Halictus confusus & Species & $F_{1,15}=0.78 ; p=0.3897$ & $1.5(0.39)$ & $1.0(0.38)$ \\
\hline & L. albipenne & Species & $F_{1,49}=1.81 ; p=0.1847$ & $1.93(0.25)$ & $1.43(0.26)$ \\
\hline & L. pruinosum & Species & $F_{1,65}=0.17 ; p=0.6774$ & $1.48(0.17)$ & $1.33(0.30)$ \\
\hline & L. semicaeruleum & Species & $F_{1,78}=4.89 ; p=0.0299$ & $1.91(0.18)$ & $1.18(0.23)$ \\
\hline & Megachile brevis & Species & $F_{1,62}=0.16 ; p=0.6893$ & $1.45(0.36)$ & $1.62(0.17)$ \\
\hline \multirow[t]{2}{*}{ Eriogonum visheri } & Calliopsis andreniformis & Species & $F_{1,67}=7.51 ; p=0.0079$ & $2.56(0.27)$ & $1.6(0.21)$ \\
\hline & L. packeri & Species & $F_{1,103}=0.16 ; p=0.6905$ & $2.7(0.16)$ & $2.4(0.69)$ \\
\hline \multirow[t]{3}{*}{ Ericameria parryi } & Bombus huntii & Family & $F_{1,19}=0.07 ; p=0.7949$ & $1(0.41)$ & $1.13(0.27)$ \\
\hline & Lasioglossum packeri & Family & $F_{1,13}=0 ; p=1.0$ & $1(0.32)$ & $1(0.45)$ \\
\hline & Melissodes glenwoodensis & Family & $F_{1,10}=1.36 ; p=0.2705$ & $1.8(0.6)$ & $1(0.38)$ \\
\hline \multirow[t]{6}{*}{ Cirsium arvense } & Augochlorella aurata & Family & $F_{1,103}=0.23 ; p=0.6307$ & $1.23(0.14)$ & $1.12(0.17)$ \\
\hline & Halictus confusus & Family & $F_{1,15}=0.04 ; p=0.8464$ & $1.1(0.33)$ & $1.0(0.38)$ \\
\hline & Lasioglossum albipenne & Family & $F_{1,49}=0.57 ; p=0.4558$ & $1.33(0.21)$ & $1.1(0.23)$ \\
\hline & Lasioglossum pruinosum & Family & $F_{1,65}=0.32 ; p=0.5718$ & $1.25(0.16)$ & $0.17(0.27)$ \\
\hline & Lasioglossum semicaeruleum & Family & $F_{1,78}=2.55 ; p=0.1141$ & $1.47(0.16)$ & $1(0.21)$ \\
\hline & Megachile brevis & Family & $F_{1,62}=0.08 ; p=0.7766$ & $1.27(0.34)$ & $1.17(0.15)$ \\
\hline \multirow[t]{2}{*}{ Eriogonum visheri } & Calliopsis andreniformis & Family & $F_{1,67}=10.04 ; p=0.0023$ & $2.32(0.26)$ & $1.29(0.19)$ \\
\hline & Lasioglossum packeri & Family & $F_{1,103}=0.11 ; p=0.7832$ & $1.38(0.12)$ & $1.2(0.49)$ \\
\hline
\end{tabular}

Means in bold indicate female and male means were significantly different from each other $(p \leq 0.05)$ 
a

E. parryi sites

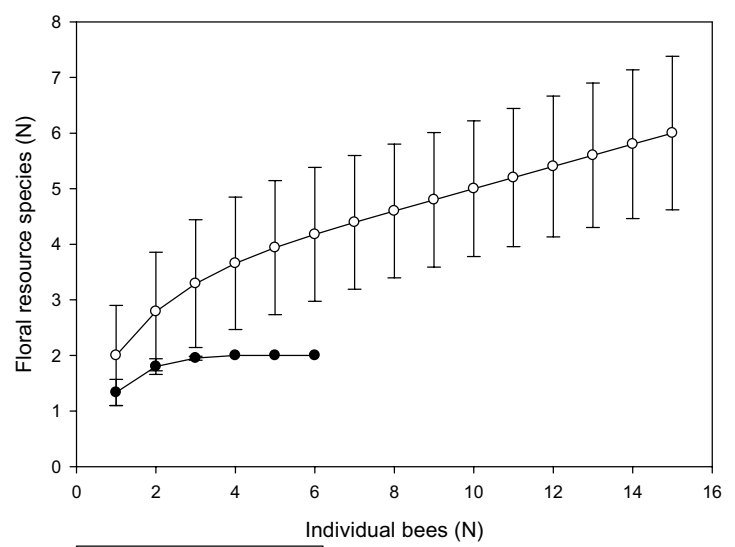

$\rightarrow$ Bombus huntii female $\rightarrow-$ Bombus huntii male

C

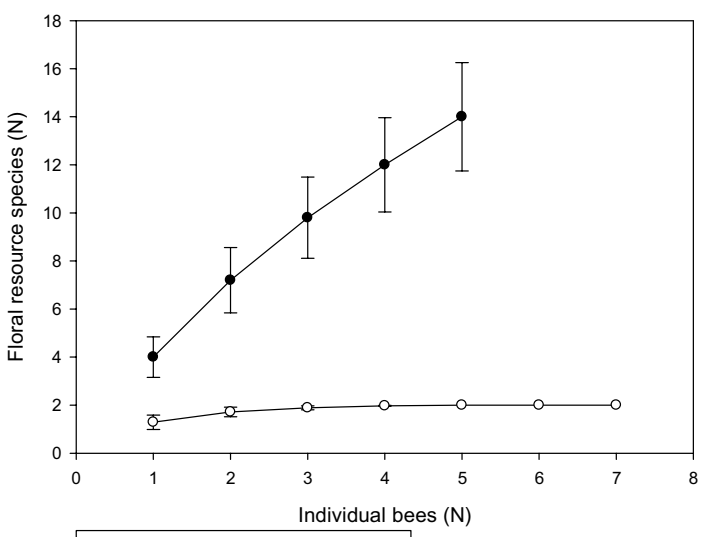

$\rightarrow-$ Melissodes glenwoodensis female $\rightarrow-$ Melissodes glenwoodensis male

e

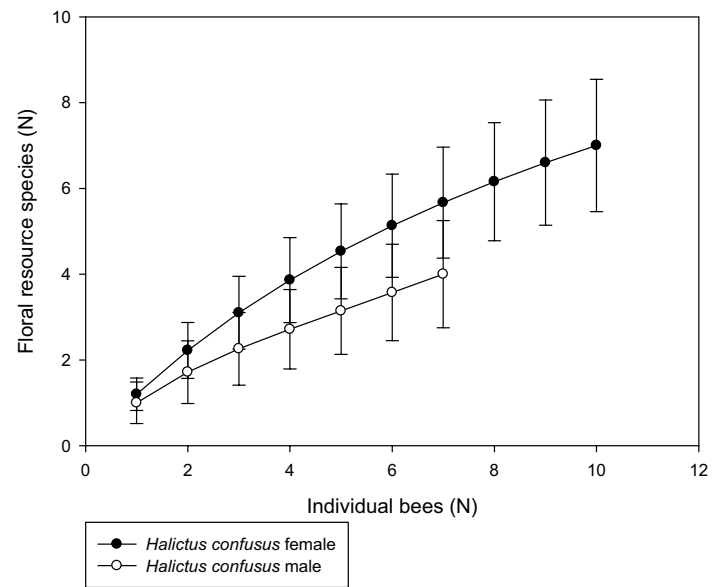

Fig. 1 Estimated floral resource species accumulated with each additional female or male bee of species with $\geq 5$ individuals of each sex at Ericameria parryi $(\mathbf{a}-\mathbf{c})$, Cirsium arvense $(\mathbf{d}-\mathbf{i})$, and Eriogonum b

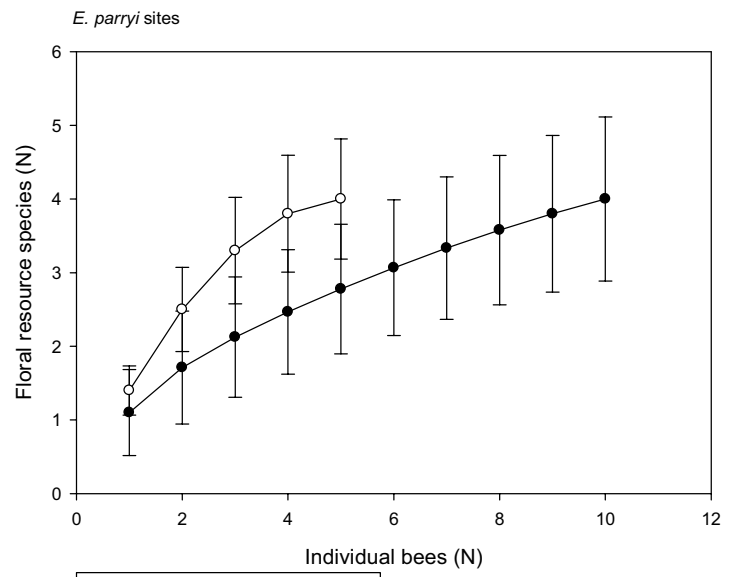

$\rightarrow-$ Lasioglossum packeri female - Lasioglossum packeri male

d C. arvense sites

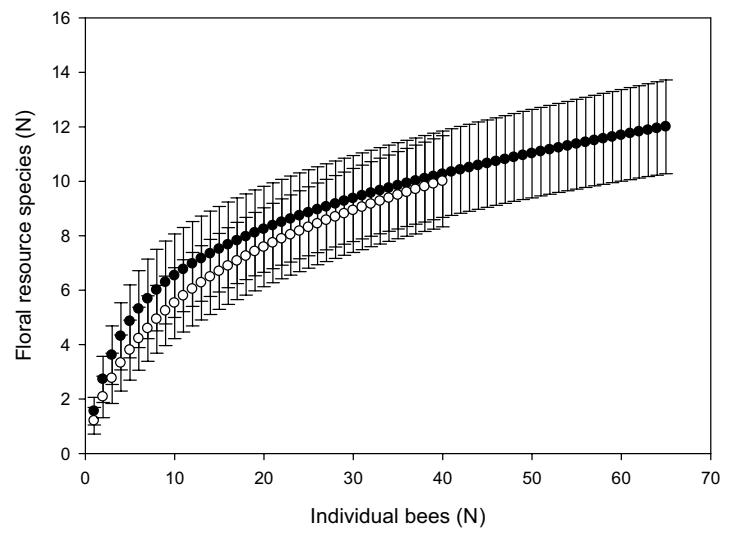

- Augochlorella aurata female Augochlorella aurata male

f

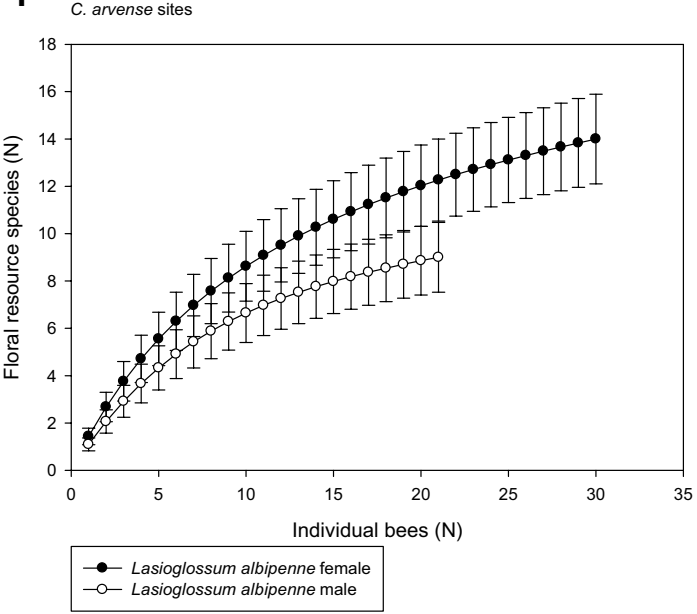

visheri $(\mathbf{j}-\mathbf{k})$ sites. Shown are mean \pm standard deviation for female (closed dots) and male (open dots) bees 

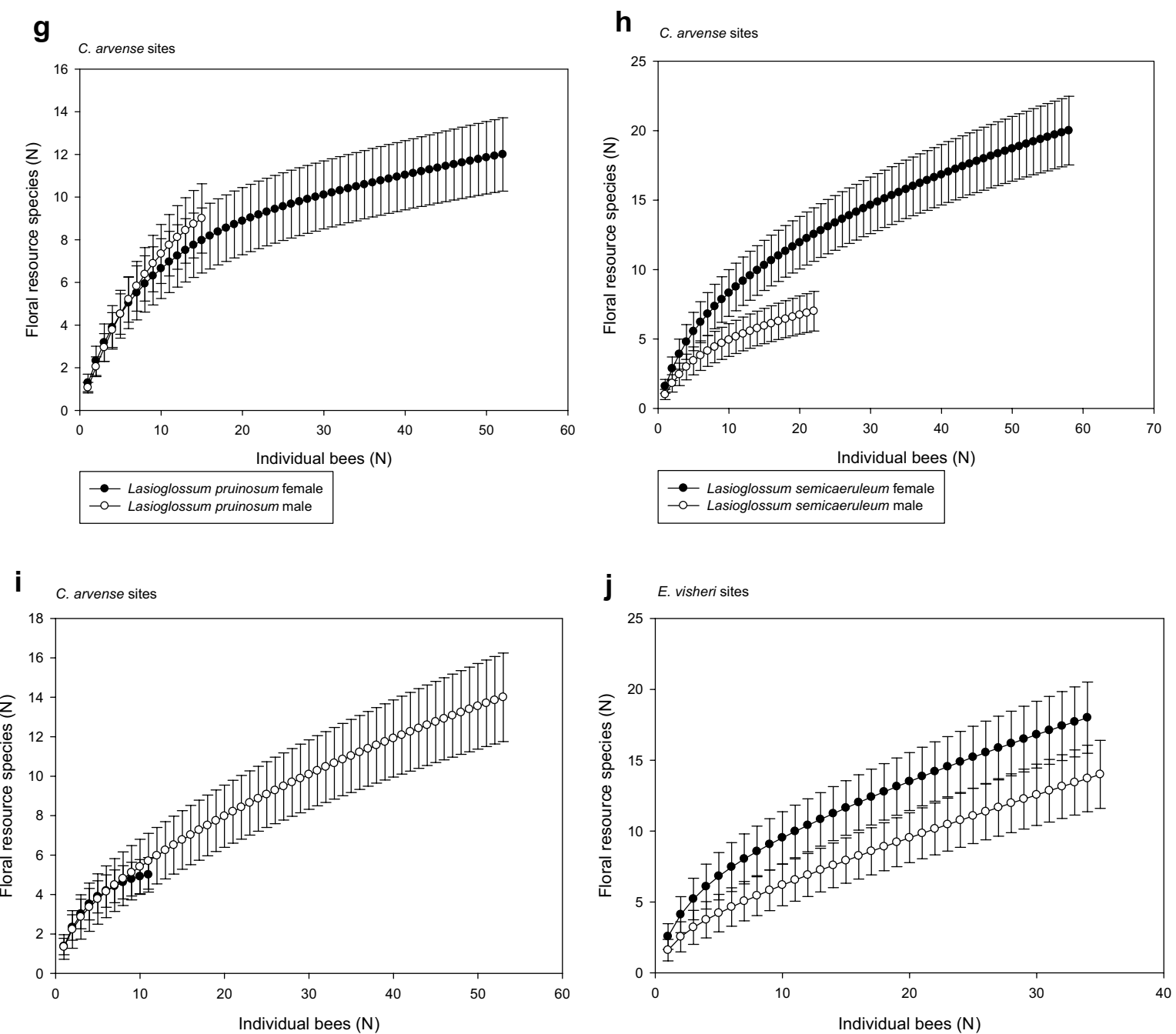

Individual bees $(\mathrm{N})$

- Megachile brevis female

$\rightarrow$ Calliopsis andreniformis female Calliopsis andreniformis male

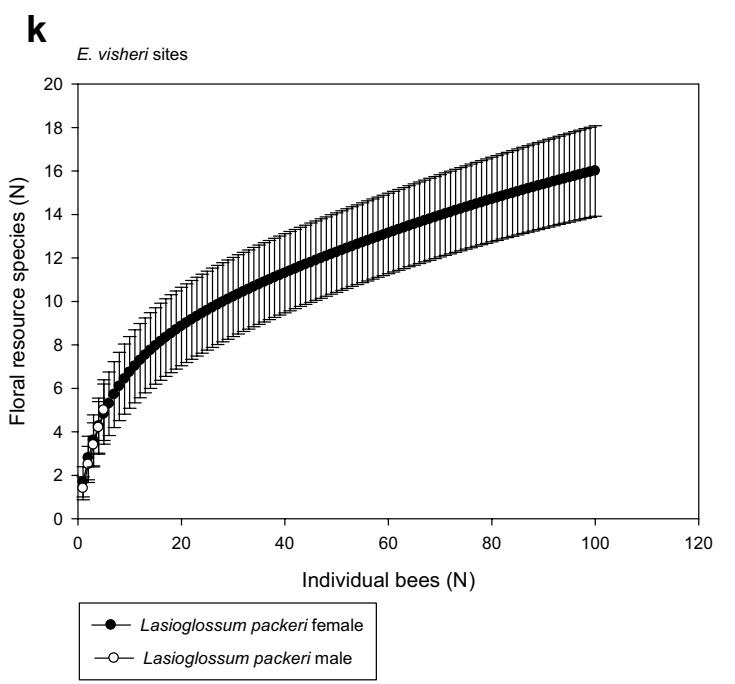

Fig. 1 (continued) 


\section{a Bombus huntii at Ericameria parryi sites}

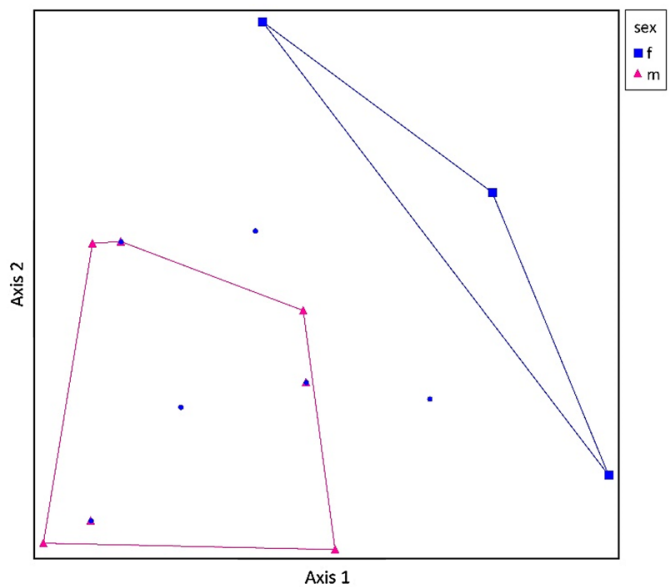

C Melissodes glenwoodensis at Ericameria parryi sites

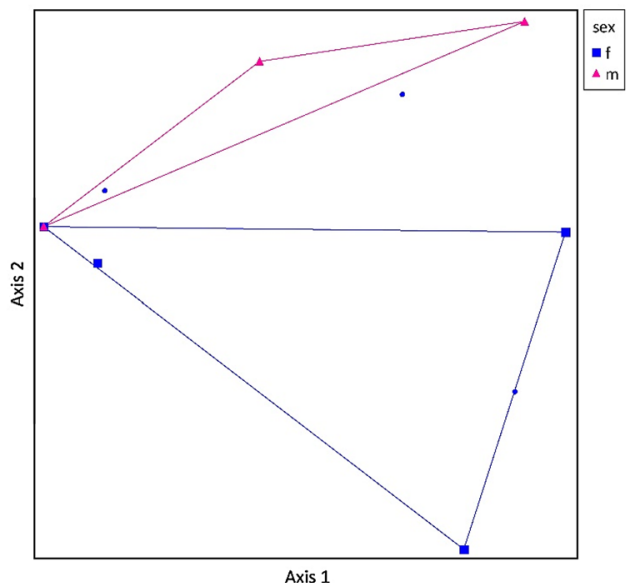

e Halictus confusus at Cirsium arvense sites

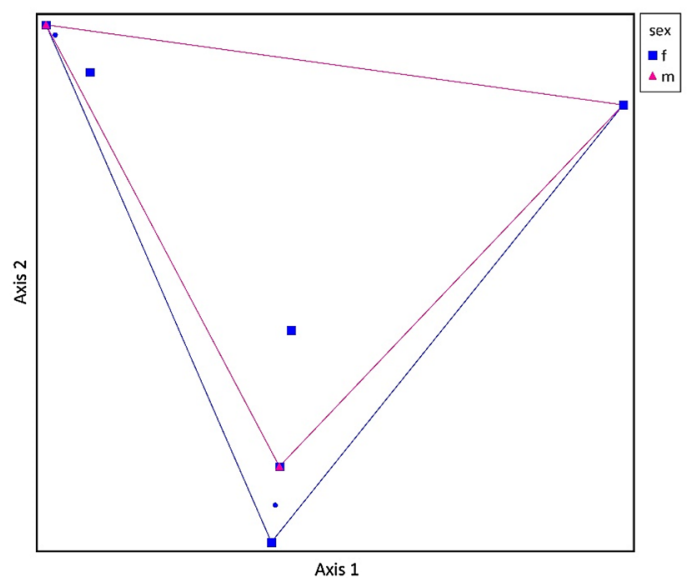

Fig. 2 Principal coordinates analysis for bee species used in rarefaction graphs. Small blue dots represent floral resource species, blue squares represent female (f) bees and magenta triangles represent male ( $\mathrm{m}$ ) bees. Blue and magenta envelopes enclose all individuals of female and male bees, respectively. a Bombus huntii at Ericameria parryi sites. b Lasioglossum packeri at Ericameria parryi sites. c Melissodes glenwoodensis at

\section{b Lasioglossum packeri at Ericameria parryi sites}

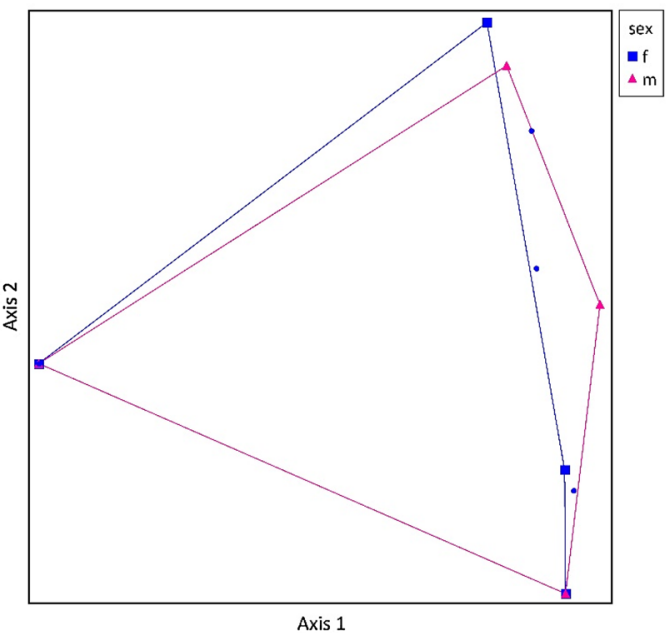

d Augochlorella aurata at Cirsium arvense sites

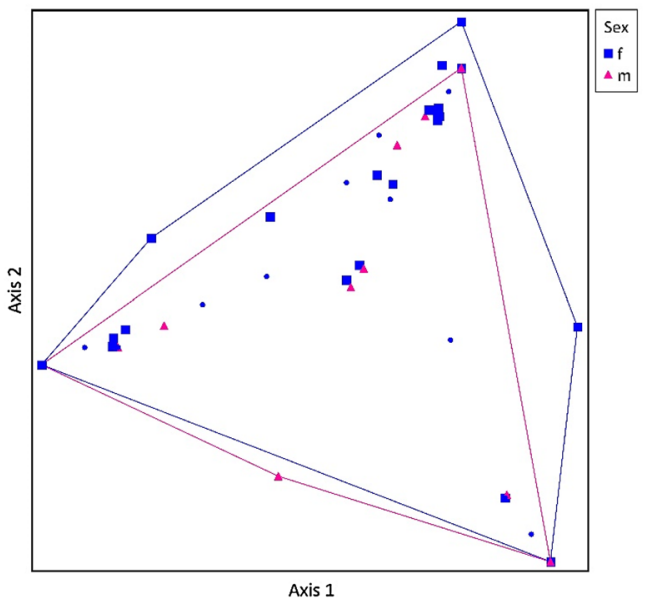

f Lasioglossum albipenne at Cirsium arvense sites

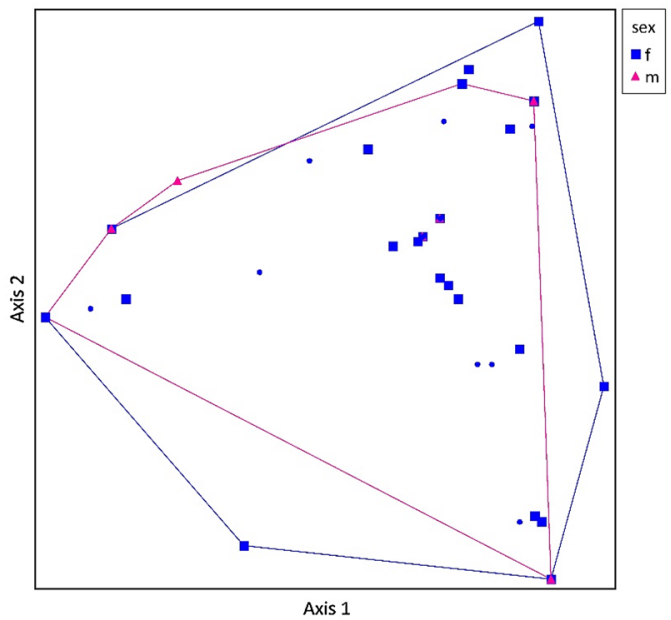

Ericameria parryi sites. d Augochlorella aurata at Cirsium arvense sites. e Halictus confusus at Cirsium arvense sites. f Lasioglossum albipenne at Cirsium arvense sites. $\mathbf{g}$ Lasioglossum pruinosum at Cirsium arvense sites. h Lasioglossum semicaeruleum at Cirsium arvense sites. i Megachile brevis at Cirsium arvense sties. $\mathbf{j}$ Calliopsis andreniformis at Eriogonum visheri sites. $\mathbf{k}$ Lasioglossum packeri at Eriogonum visheri sites 
g Lasioglossum pruinosum at Cirsium arvense sites

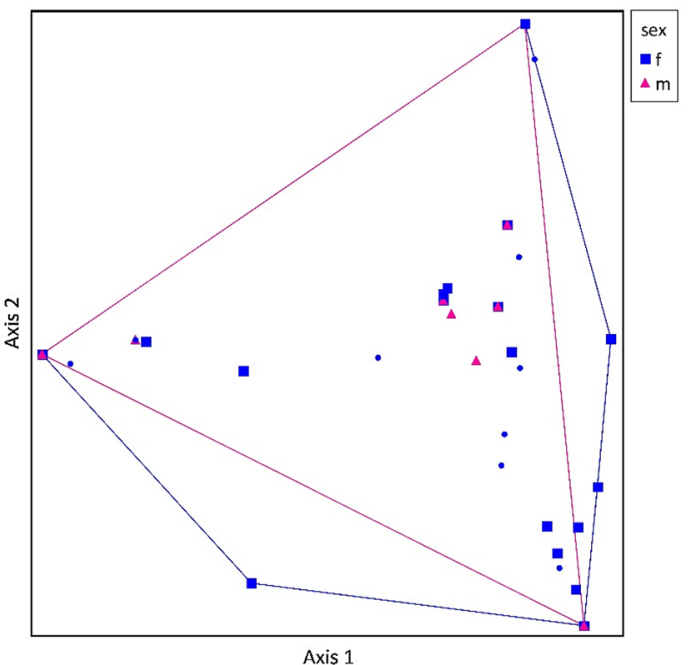

i Megachile brevis at Cirsium arvense sties

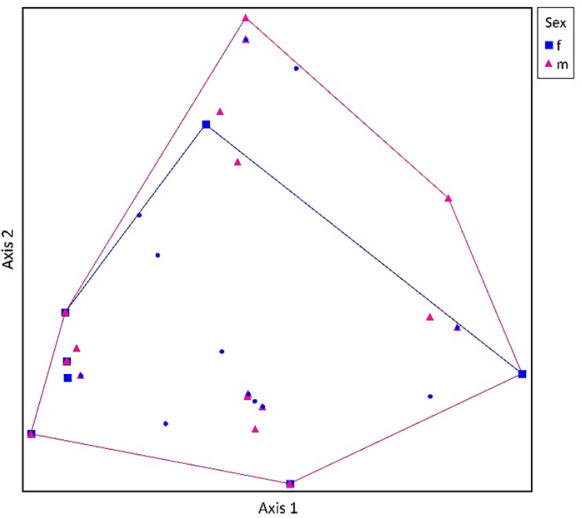

h Lasioglossum semicaeruleum at Cirsium arvense sites

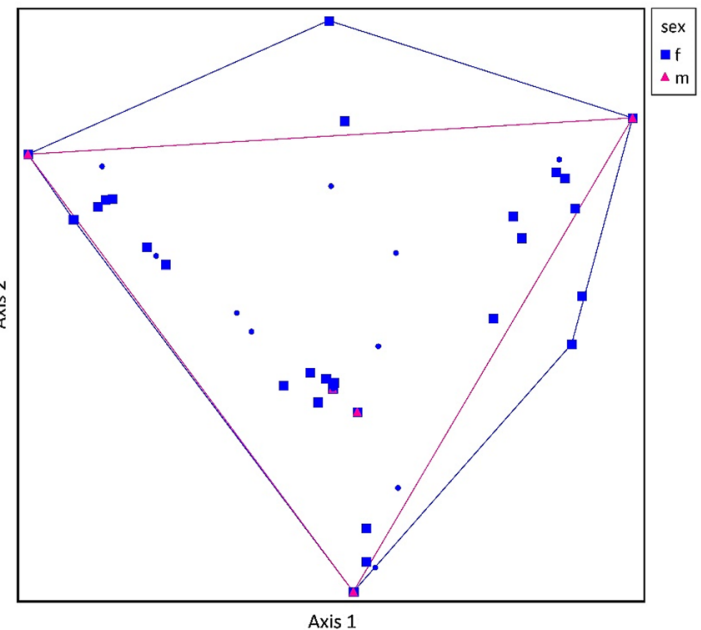

j Calliopsis andreniformis at Eriogonum visheri sites

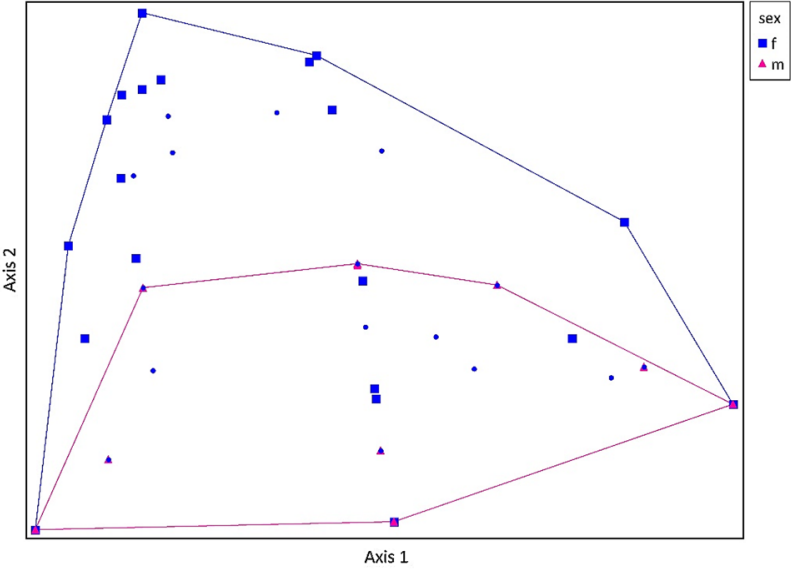

K Lasioglossum packeri at Eriogonum visheri sites

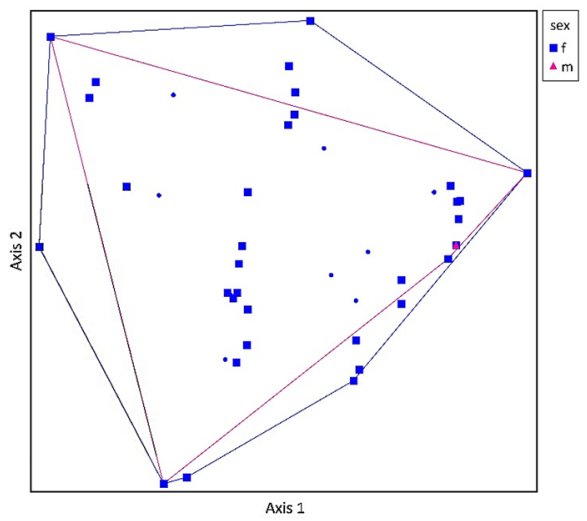

Fig. 2 (continued)

accumulated fewer floral resource species (Fig. 1j) and families (Figure S1j) than females at E. visheri sites.

Principal coordinates analysis illustrated patterns similar to those we found in the rarefaction curves. Most species in the Halictidae had broadly overlapping diet extents between males and females (Fig. 2). In contrast, B. huntii, M. glenwoodensis, and C. andreniformis plots (Fig. 2a, c, and j, respectively) illustrated less overlap in male and female 
Table 3 Modularity of networks with and without bee species separated by sex

\begin{tabular}{|c|c|c|c|c|c|c|}
\hline Study & Network type & Modules (N) & Observed modularity & Random modularity & Sigma & $p$ \\
\hline \multirow[t]{2}{*}{ Ericameria parryi } & Separate sexes & 7 & 0.327358 & 0.334378 & 0.004393 & $1.81 \mathrm{E}-29$ \\
\hline & Combined sexes & 6 & 0.317668 & 0.337359 & 0.004605 & $6.18 \mathrm{E}-66$ \\
\hline \multirow[t]{2}{*}{ Cirsium arvense } & Separate sexes & 6 & 0.340141 & 0.340135 & 0.003849 & 0.493797 \\
\hline & Combined sexes & 7 & 0.335003 & 0.325443 & 0.00473 & $3.26 \mathrm{E}-37$ \\
\hline \multirow[t]{2}{*}{ Eriogonum visheri } & Separate sexes & 7 & 0.415894 & 0.399936 & 0.004922 & $7.89 \mathrm{E}-55$ \\
\hline & Combined sexes & 8 & 0.411118 & 0.393979 & 0.004715 & $2.28 \mathrm{E}-59$ \\
\hline
\end{tabular}

floral use. Even when the floral resource use extents varied little between females and males, male extent was enclosed within female extent, with the exception of $M$. brevis (Fig. 2i), where female extent was a subset of male extent and $L$. packeri at E. parryi sites (Fig. 2b), where male extent slightly exceeded female extent.

When sexes were separated, all networks except $C$. arvense sites were significantly more modular than randomly assembled networks (Table 3). When bees were separated by sex, networks at $C$. arvense and $E$. visheri sites had one fewer module than when sexes were combined by species; the opposite was true at E. parryi sites (Table 3). In seven of the eleven bee species-study combinations, when sexes were separated, they occupied different modules (Table 4). Lasioglossum packeri females and males occupied the same module when analyzed separately at $E$. parryi sites, but different modules at $E$. visheri sites. Roles changed for females twice and for males three times compared to modularity analyses where sexes were not separated (Table 4). Nearly all bee species, whether or not separated by sex, occupied connector roles; only three times were they peripherals, and these happened when sexes were separated. The two specialists, M. glenwoodensis and C. andreniformis, were hubs when grouped by species; female $M$. glenwoodensis retained the hub role when separated from males, which were peripheral in a different module (Table 4). The proportion of nodes classified as hubs did not change in networks at any of the three sites, but proportion of connectors declined, and peripherals increased when sexes were separated at E. parryi and E. visheri sites (Table S2).

\section{Discussion}

Of the 11 species-study combinations, individual femaleand male-conspecific bees differed in the number of floral resource species they used three times, and in floral families only once. This implies that, on average, females and males of most species we studied had visited a similar number of distinct flower species or families when captured. Of the exceptions, the specialists $M$. glenwoodensis at E. parryi sites and $C$. andreniformis at $E$. visheri sites also differed in floral resource accumulation curves: females of both of these species carried and accumulated more floral resource species than did males. Contrary to our expectations, and the predictions of Smith et al. (2019b), in no cases did individual males visit more plant species or families than females. In general, males and females visited similar numbers of plant species, both as individuals and collectively as a species. We had expected the females of at least some species to be pickier foragers than males because males are primarily seeking nectar for their own energetic needs, whereas we expected females to restrict themselves more to flowers that are their pollen hosts. For example, in the Alkali Bee (Nomia melanderi), males visit a wider variety of nectar sources than females, which primarily take nectar from their pollen hosts (Stephen et al. 1969). Only in the generalist $B$. huntii did males accumulate more pollen species than did females. Although Smith et al. (2019b) hypothesized that females would have a smaller diet breadth than males, they also posited reasons the opposite might be true. If females' foraging decisions are based on varying nutritional quality of pollen, they might forage more broadly than males to achieve the desired quality for nest provision. Smith et al. (2019b) also recognized that oviposition sites might influence pollen choice. Locating nests and determining the nutritional value of the provisions therein to evaluate these alternatives were beyond the scope of the current study. There is a great need for such detailed natural history studies.

Our results largely do not align with the findings by Roswell et al. (2019) that males and females commonly have major differences in foraging preferences. Instead, we found that males and females generally aligned in their foraging preferences. However, part of this may be due to differences in study design. Roswell et al. (2019) conducted their study in meadows in New Jersey, whereas the present study was conducted in the badlands of South Dakota, which was less florally diverse. In addition, our practice of reconstructing visitation using pollen on the body rather than just observed visitation captured the resource use history of a given forager and may have provided a better assessment of less commonly used floral hosts that may be otherwise overlooked (e.g. those with flowers that are only open for a brief period in the early morning). Finally, because our methods depend 
Table 4 Module affiliation in networks with and without bee sexes separated

\begin{tabular}{|c|c|c|c|c|c|}
\hline Study & Bee species & Network type & $\operatorname{Sex}^{\mathrm{a}}$ & Role $^{\mathrm{b}}$ & Module hub(s) \\
\hline \multirow[t]{9}{*}{ Ericameria parryi } & Bombus huntii & Combined sexes & & $\mathrm{C}$ & Polistes aurifer \\
\hline & & Separated sexes & $\mathrm{F}$ & $\mathrm{P}$ & Grindelia squarrosa / Gutierrezia sarothrae \\
\hline & & & M & $\mathrm{C}$ & Polistes aurifer \\
\hline & Lasioglossum packeri & Combined sexes & & $\mathrm{C}$ & Gutierrezia sarothrae \\
\hline & & Separated sexes & $\mathrm{F}$ & $\mathrm{C}$ & Grindelia squarrosa / Gutierrezia sarothrae \\
\hline & & & M & $\mathrm{C}$ & Grindelia squarrosa / Gutierrezia sarothrae \\
\hline & Melissodes glenwoodensis & Combined sexes & & $\mathrm{H}$ & M. glenwoodensis/Ericameria nauseosus \\
\hline & & Separated sexes & $\mathrm{F}$ & $\mathrm{H}$ & M. glenwoodensis/Ericameria nauseosus \\
\hline & & & M & $\mathrm{P}$ & E. Parryi \\
\hline \multirow[t]{18}{*}{ Cirsium arvense } & Augochlorella aurata & Combined sexes & & $\mathrm{C}$ & $\begin{array}{l}\text { Cirsium flodmanii/ Convolvulus arvensis / Helianthus } \\
\text { annuus }\end{array}$ \\
\hline & & Separated sexes & $\mathrm{F}$ & $\mathrm{C}$ & $\begin{array}{l}\text { Cirsium flodmanii/ Convolvulus arvensis / Helianthus } \\
\text { аппииs }\end{array}$ \\
\hline & & & M & $\mathrm{C}$ & $\begin{array}{l}\text { Cirsium flodmanii/ Convolvulus arvensis / Helianthus } \\
\text { annuus }\end{array}$ \\
\hline & Halictus confusus & Combined sexes & & $\mathrm{C}$ & $\begin{array}{l}\text { Cirsium flodmanii/ Convolvulus arvensis / Helianthus } \\
\text { апnuus }\end{array}$ \\
\hline & & Separated sexes & $\mathrm{F}$ & $\mathrm{C}$ & Melilotus officinalis \\
\hline & & & M & $\mathrm{C}$ & Melilotus officinalis \\
\hline & Lasioglossum albipenne & Combined sexes & & $\mathrm{C}$ & Formica BADL2-Pediomelum argophyllum \\
\hline & & Separated sexes & $\mathrm{F}$ & $\mathrm{C}$ & $\begin{array}{l}\text { Cirsium flodmanii/ Convolvulus arvensis / Helianthus } \\
\text { апnиus }\end{array}$ \\
\hline & & & M & $\mathrm{C}$ & Cirsium arvense \\
\hline & Lasioglossum pruinosum & Combined sexes & & $\mathrm{C}$ & $\begin{array}{l}\text { Cirsium flodmanii/ Convolvulus arvensis / Helianthus } \\
\text { апnиus }\end{array}$ \\
\hline & & Separated sexes & $\mathrm{F}$ & $\mathrm{C}$ & $\begin{array}{l}\text { Cirsium flodmanii/ Convolvulus arvensis / Helianthus } \\
\text { апnиus }\end{array}$ \\
\hline & & & M & $\mathrm{C}$ & $\begin{array}{l}\text { Cirsium flodmanii/ Convolvulus arvensis / Helianthus } \\
\text { апnuus }\end{array}$ \\
\hline & Lasioglossum semicaeruleum & Combined sexes & & $\mathrm{C}$ & $\begin{array}{l}\text { Cirsium flodmanii/ Convolvulus arvensis / Helianthus } \\
\text { апnuus }\end{array}$ \\
\hline & & Separated sexes & $\mathrm{F}$ & $\mathrm{C}$ & Formica obscuripes/Medicago sativa \\
\hline & & & M & $\mathrm{C}$ & Cirsium arvense \\
\hline & Megachile brevis & Combined sexes & & $\mathrm{C}$ & Medicago sativa \\
\hline & & Separated sexes & $\mathrm{F}$ & $\mathrm{C}$ & Melilotus officinalis \\
\hline & & & M & $\mathrm{C}$ & Formica obscuripes/ Medicago sativa \\
\hline \multirow[t]{6}{*}{ Eriogonum visheri } & Calliopsis andreniformis & Combined sexes & & $\mathrm{H}$ & Calliopsis andreniformis \\
\hline & & Separated sexes & $\mathrm{F}$ & $\mathrm{C}$ & Astragalus racemosus \\
\hline & & & M & $\mathrm{C}$ & Agapostemon angelicus/texanus female \\
\hline & Lasioglossum packeri & Combined sexes & & $\mathrm{C}$ & No hub \\
\hline & & Separated sexes & $\mathrm{F}$ & $\mathrm{C}$ & Grindelia squarrosa \\
\hline & & & M & $\mathrm{P}$ & Eriogonum pauciflorum/E. visheri \\
\hline
\end{tabular}

${ }^{\text {a }} F$ female, $M$ male

${ }^{\mathrm{b}} H$ hub, $C$ connector, $P$ peripheral

on visitation history, differences between male and female grooming habits could potentially influence our results. If females are more fastidious groomers due to their provisioning behavior, then males could be retaining pollen for longer periods. However, we do not expect this to be a major effect since females have been found to retain pollen on their bodies even after depositing pollen in the brood cell (Cane and Love 2019).

Two of the ten species with $\geq 5$ individuals per sex were pollen specialists (oligolectic) - C. andreniformis and $M$. glenwoodensis - who provision their young with pollen from a single plant family. Calliopsis andreniformis visits a wide 
variety of plants, but analysis of female pollen loads indicates that it is a specialist on pollen from the Fabaceae, particularly from the non-native genera Trifolium and Melilotus (Shinn 1967; Dyer and Shinn 1978); C. andreniformis overwhelmingly visited $M$. officinalis at $C$. arvense sites, as well (38 of 41 Fabaceae floral resources recorded were M. officinalis). Nonetheless, host (Fabaceae) resource use was detected on only 15 of 35 females and 23 of 36 males. This is consistent with research by Smith et al. (2019a) that unexpectedly found a high diversity of non-host pollen on some oligolectic bees. Melissodes glenwoodensis is specialized on the pollen of Asteraceae, particularly the genus Ericameria (formerly Chrysothamnus; Moldenke 1979; Hurd et al. 1980). Our sample size is small for M. glenwoodensis, but we detected host pollen on all captured females and males. In both cases, we found that males visited a subset of the plant species visited by females. Following the predictions of Smith et al. (2019b), we expected that males would visit more plants than females because they would nectar opportunistically whereas females would take nectar primarily from their pollen sources. This was not the case, as both males and females visited a variety of plants unrelated to their pollen hosts. Nutritional quality of the pollen collected by females of these species might shed light on the patterns we observed (Smith et al. 2019b).

Similar to the pollen-specialist bees, patterns of male and female visitation were similar in generalist (polylectic) species, with individual males and females visiting similar numbers of flower species and males typically visiting a subset of flower species that females visited. An interesting exception was $L$. semicaeruleum, the only member of the family Halictidae in which individual females visited more flower species than did males and females accumulated more floral resources than did males. The modularity analysis also separated $L$. semicaeruleum females and males into different modules, though principal coordinate analysis illustrated substantial overlap between floral use extents of males and females. We found no information on foraging or diet of this widespread species with which to compare our results, although Gibbs (2010) provides a list of plant species on which the bee has been recorded. Another generalist bee in which males and females differed substantially was $B$. huntii. In this case, patrolling behavior by males may be instrumental in determining their foraging strategy (Williams et al. 2014).

Availability of floral resource species at the different study sites undoubtedly influenced resource use, but our data were not suitable to formally analyze preference. Of 13 Lasioglossum putative species across $C$. arvense and E. parryi sites, only three were shared across the two sites and none of these had adequate representation of both females and males for within-species comparison across sites. The limited floral diversity at $E$. parryi sites, which clustered within only three plant families (Asteraceae, Chenopodiaceae, and Polygonaceae), likely selected for bees that could make use of the floral resources available (Ritchie et al. 2016) and possibly limited our ability to detect differences between sexes. Lasioglossum packeri used far fewer floral resources at the $E$. parryi sites than at the E. visheri sites, based on floral resource rarefaction curves, likely because of limited diversity (Cullen et al. 2021) as noted above. Despite abundant flowers, floral resources in the Chenopodiaceae were never used by $L$. packeri at $E$. parryi sites but were commonly used at E. visheri sites by both sexes. Modularity results for Lasioglossum species revealed that for some species, females and males separated into different modules, while others did not. This suggests that, even though the genus is considered to be composed primarily of generalists (Michener 2007), Lasioglossum species may still have important differences in foraging strategies. Gibbs (2010) noted that sexual dimorphism in Lasioglossum can make taxonomy difficult, but it could as well make it likely that males and females forage differently, despite being generalists.

Our modularity analysis calls attention to potential issues of lumping sexes within species, recognized by Roswell et al. (2019). Even though sexes of most species we studied overlapped in floral resources visited, details of the interactions resulted in separation of sexes into different modules in seven of the eleven species-study combinations we highlighted in the other analyses. Nonetheless, roles changed relatively rarely when sexes were separated, but when they did, the proportion of connectors declined, and the proportion of peripherals increased, which indicates that connections among modules were rewired when module affiliation changed. If separating sexes changes the wiring of a network such that roles and modules are affected, conclusions about stability of pollinator communities, especially regarding propagation of disturbances across modules, may be incorrect (Sheykhali et al. 2020). Hemprich-Bennett et al. (2021) discussed the importance of species-level node resolution; sex may be another aspect of resolution to be considered.

\section{Conclusions}

We demonstrate, for a small number of bee species in two distinct habitats, that females and males for the most part forage similarly; when they do not, females, with few exceptions, visit more floral taxa than males. Ranges of all of these bees extend well beyond the areas we observed at BNP and we make no claim to species-wide patterns in female versus male diet breadth. Foraging by bee species is known to be contingent on plant community composition (Albrecht et al. 2014; Albrecht 2016), which may explain differential foraging on Chenopodiaceae by $L$. packeri at $E$. visheri and $E$. parryi sites. Nonetheless, our results suggest that 
generalization is unwise; differences in foraging between the sexes did not follow predicable patterns based on known life history traits; this picture may change as our understanding of bee life history improves.

Supplementary Information The online version contains supplementary material available at https://doi.org/10.1007/s11829-021-09881-x.

Acknowledgements We thank the field assistants, volunteers, and interns who made this study possible. We are grateful to Badlands National Park for permitting us to work there. Sam Droege and Jelle Devalez identified the insects with taxonomic assistance from John Ascher, Jason Gibbs, Terry Griswold, and Karen Wright. Ian Lane and an anonymous reviewer provided helpful advice on an earlier version of this paper. Funding was provided by U.S. Geological Survey Natural Resources Protection Program/Park-oriented Biological Support, U.S. Geological Survey Invasive Species Program, Northern Prairie Wildlife Research Center, and Patuxent Wildlife Research Center. Any use of trade, firm, or product names is for descriptive purposes only and does not imply endorsement by the U.S. Government.

Open Access This article is licensed under a Creative Commons Attribution 4.0 International License, which permits use, sharing, adaptation, distribution and reproduction in any medium or format, as long as you give appropriate credit to the original author(s) and the source, provide a link to the Creative Commons licence, and indicate if changes were made. The images or other third party material in this article are included in the article's Creative Commons licence, unless indicated otherwise in a credit line to the material. If material is not included in the article's Creative Commons licence and your intended use is not permitted by statutory regulation or exceeds the permitted use, you will need to obtain permission directly from the copyright holder. To view a copy of this licence, visit http://creativecommons.org/licenses/by/4.0/.

\section{References}

Albrecht M, Padron B, Bartomeus I et al (2014) Consequences of plant invasions on compartmentalization and species' roles in plantpollinator networks. Proc R Soc B-Biol Sci. https://doi.org/10. 1098/rspb.2014.0773

Albrecht M, Ramis MR, Traveset A (2016) Pollinator-mediated impacts of alien invasive plants on the pollination of native plants: The role of spatial scale and distinct behaviour among pollinator guilds. Biol Invasions 18:1801-1812. https://doi.org/10.1007/ s10530-016-1121-6

Araujo MS, Bolnick DI, Layman CA (2011) The ecological causes of individual specialisation. Ecol Lett 14:948-958. https://doi.org/ 10.1111/j.1461-0248.2011.01662.x

Blüthgen N, Menzel F, Blüthgen N (2006) Measuring specialization in species interaction networks. BMC Ecol 6:9. https://doi.org/10. 1186/1472-6785-6-9

Cane JH, Love B (2019) Pollen carryover between sequential foraging trips by a solitary bee: implications for distant outcrossing. J Poll Ecol 24:136-143

Cullen N, Xia J, Wei N et al (2021) Diversity and composition of pollen loads carried by pollinators are primarily driven by insect traits, not floral community characteristics. Oecologia. https://doi.org/ 10.1007/s00442-021-04911-0:13

Dupont YL, Olesen JM (2009) Ecological modules and roles of species in heathland plant-insect flower visitor networks. J Animal Ecol 78:346-353
Dupont YL, Olesen JM (2012) Stability of modular structure in temporal cumulative plant-flower-visitor networks. Ecol Complex 11:84-90. https://doi.org/10.1016/j.ecocom.2012.03.004

Dyer JG, Shinn AF (1978) Pollen collected by Calliopsis andreniformis Smith in North America (Hymenoptera: Andrenidae). J Kasas Entomol Soc 51:787-795

Gibbs J (2010) Revision of the metallic species of Lasioglossum (Dialictus) in Canada (Hymenoptera, Halactidae, Halictini). 2591:1-382

Greenleaf SS, Williams NM, Winfree R et al (2007) Bee foraging ranges and their relationship to body size. Oecologia 153:589596. https://doi.org/10.1007/s00442-007-0752-9

Grilli J, Rogers T, Allesina S (2016) Modularity and stability in ecological communities. Nat Commun 7:12031. https://doi.org/10. 1038/ncomms 12031

Guimera R, Amaral LAN (2005) Functional cartography of complex metabolic networks. Nature 433:895-900. https://doi.org/10.1038/ nature 03288

Guimera R, Sales-Pardo M, Amaral LAN (2007) Classes of complex networks defined by role-to-role connectivity profiles. Nat Phys 3:63-69. https://doi.org/10.1038/nphys489

Helms KR (1994) Sexual size dimorphism and sex ratios in bees and wasps. Am Nat 143:418-434. https://doi.org/10.1086/285611

Hemprich-Bennett DR, Oliveira HFM, Le Comber SC et al (2021) Assessing the impact of taxon resolution on network structure. Ecology 102:15. https://doi.org/10.1002/ecy.3356

Hurd PD, LaBerge WE, Linsly EG (1980) Principal sunflower bees of North America with emphasis on the southwestern United States (Hymenoptera: Apoidea). Smithsonian Contributions Zoo 310:1-158

Jennersten O, Morse DH, Oneil P (1991) Movements of male and worker bumblebees on and between flowers. Oikos 62:319-324. https://doi.org/10.2307/3545496

Kishi S, Kakutani T (2020) Male visitors may decrease modularity in flower-visitor networks. Front Ecol Evol. https://doi.org/10.3389/ fevo.2020.00124

Kraus FB, Wolf S, Moritz RFA (2009) Male flight distance and population substructure in the bumblebee Bombus terrestris. J Anim Ecol 78:247-252. https://doi.org/10.1111/j.1365-2656.2008.01479.x

Larson DL, Droege S, Rabie PA et al (2014) Using a network modularity analysis to inform management of a rare endemic plant in the northern Great Plains, USA. J Appl Ecol 51:1024-1032. https:// doi.org/10.1111/1365-2664.12273

Larson DL, Rabie PA, Droege S et al (2016) Exotic plant infestation is associated with decreased modularity and increased numbers of connectors in mixed-grass prairie pollination networks. PLoS ONE. https://doi.org/10.1371/journal.pone.0155068

Larson DL, DA Buhl, Larson JL (2018) Variation in pollen transport, Badlands NP, 2018, U.S. Geological Survey Data Release. https:// doi.org/10.5066/P9YM2XL4.

Latty T, Trueblood JS (2020) How do insects choose flowers? A review of multi-attribute flower choice and decoy effects in flower-visiting insects. J Anim Ecol 89:2750-2762. https://doi.org/10.1111/ 1365-2656.13347

Linsley EG, MacSwain JW (1958) The significance of floral constancy among bees of the genus Diadasia (Hymenoptera, Anthrophoridae). Evolution 12:219-223. https://doi.org/10.1111/j.1558-5646. 1958.tb02948.x

McCune B, MJ Mefford. (2018) Pc-ord. Multivariate analysis of ecological data, version 7.08, MjM Software Design, Gleneden Beach, Oregon

McCune B, Grace JB (2002) Analysis of ecological communities. MjM Software Design, Gleneden Beach, Oregon

Michener CD (2007) The bees of the world. The Johns Hopkins University Press, Baltimore, MD 
Moldenke AR (1979) Host-Plant Coevolution and the Diversity of Bees in Relation to the Flora of North America 43:357-419

Ne'eman G, Shavit O, Shaltiel L et al (2006) Foraging by male and female solitary bees with implications for pollination. J Insect Behav 19:383-401. https://doi.org/10.1007/s10905-006-9030-7

Ogilvie JE, Thomson JD (2015) Male bumble bees are important pollinators of a late-blooming plant. Arthropod-Plant Interact 9:205213. https://doi.org/10.1007/s11829-015-9368-x

Oksanen J, F Gauilaume Blanchet, M Friendly, et al. (2020) Vegan: Community ecology package.

Paxton RJ (2005) Male mating behaviour and mating systems of bees: an overview. Apidologie 36:145-156

Peterson JH, Roitberg BD (2006) Impacts of flight distance on sex ratio and resource allocation to offspring in the leafcutter bee, Megachile rotundata. Behav Ecol Sociobiol 59:589-596. https:// doi.org/10.1007/s00265-005-0085-9

Portman ZM, Orr MC, Griswold T (2019) A review and updated classification of pollen gathering behavior in bees (Hymenoptera, Apoidea). J Hymenopt Res 71:171-208. https://doi.org/10.3897/ jhr.71.32671

R Core Team (2015) R: A language and environment for statistical computing., $\mathrm{R}$ foundation for statistical computing, Vienna, Austria. URL http://www.R-project.org/.

Rasmussen C, Engel MS, Vereecken NJ (2020) A primer of host-plant specialization in bees. Emerg Top Life Sci 4:7-17. https://doi.org/ 10.1042/etls20190118

Ritchie AD, Ruppel R, Jha S (2016) Generalist behavior describes pollen foraging for perceived oligolectic and polylectic bees. Environ Entomol 45:909-919. https://doi.org/10.1093/ee/nvw032

Roberts RB, Vallespir SR (1978) Specialization of hairs bearing pollen and oil on the legs of bees (Apoidea: Hymenoptera). Annal Entomol Soc Am 71:619-627. https://doi.org/10.1093/aesa/71.4.619

Robertson C (1925) Heterotropic Bees 6:412-436. https://doi.org/10. 2307/1929107

Roswell M, Dushoff J, Winfree R (2019) Male and female bees show large differences in floral preference. PLoS ONE 14:18. https:// doi.org/10.1371/journal.pone.0214909

SAS Institute Inc. (2018) SAS/STAT® 15.1 user's guide. SAS Institute Inc., Cary, NC, USA

Sheykhali S, Fernandez-Gracia J, Traveset A et al (2020) Robustness to extinction and plasticity derived from mutualistic bipartite ecological networks. Sci Rep 10:12. https://doi.org/10.1038/ s41598-020-66131-5

Shinn AF (1967) A revision of the bee genus Calliopsis and the biology and ecology of $C$. andreniformis (Hymenoptera:
Andrenidae). J Anim Ecol 46:753-936. https://doi.org/10.5962/ bhl.part.20081

Smith C, Weinman L, Gibbs J et al (2019a) Specialist foragers in forest bee communities are small, social or emerge early. J Anim Ecol 88:1158-1167. https://doi.org/10.1111/1365-2656.13003

Smith GP, Bronstein JL, Papaj DR (2019b) Sex differences in pollinator behavior: Patterns across species and consequences for the mutualism. J Anim Ecol 88:971-985. https://doi.org/10.1111/ 1365-2656.12988

Stephen WP, Bohart GE, Torchio PF (1969) The biology and external morphology of bees with a synopsis of the genera of north-western America. Oregon State University Agricultural Experiment Station, Corvallis, Oregon, p 140

Tang J, Quan QM, Chen JZ et al (2019) Pollinator effectiveness and importance between female and male mining bee (Andrena). Biol Lett 15:5. https://doi.org/10.1098/rsbl.2019.0479

Thébault E, Fontaine C (2010) Stability of ecological communities and the architecture of mutualistic and trophic networks. Science 329:853-856. https://doi.org/10.1126/science.1188321

Thorp RW (2000) The Collection of Pollen by Bees 222:211-223. https://doi.org/10.1007/bf00984103

Tur C, Vigalondo B, Trojelsgaard K et al (2014) Downscaling pollen-transport networks to the level of individuals. J Anim Ecol 83:306-317. https://doi.org/10.1111/1365-2656.12130

Von Loh J, D Cogan, D Faber-Langendoen et al (1999) USGS-NPS vegetation mapping program, Badlands National Park, South Dakota, US Dept. of Interior, Bureau of Reclamation, Denver, Colorado

Waser NM (1986) Flower constancy: Definition, cause, and measurement. Am Nat 127:593-603. https://doi.org/10.1086/284507

Williams PH, Thorp RW, Richardson LL et al (2014) Bumblebees of North America. Princeton University Press, Princeton, New Jersey

Zurbuchen A, Landert L, Klaiber J et al (2010) Maximum foraging ranges in solitary bees: Only few individuals have the capability to cover long foraging distances. Biol Conserv 143:669-676. https:// doi.org/10.1016/j.biocon.2009.12.003

Zurbuchen A, Cheesman S, Klaiber J et al (2010) Long foraging distances impose high costs on offspring production in solitary bees. J Anim Ecol 79:674-681. https://doi.org/10.1111/j.1365-2656. 2010.01675.x

Publisher's Note Springer Nature remains neutral with regard to jurisdictional claims in published maps and institutional affiliations. 